\title{
THE SUBSTANTIATION OF THE CONSTRUCTIVE SCHEME OF THE COMBINED UNIT FOR PREPARATION SOILS FOR SOWING OF WATER-MELON \\ Mamatov F.M. ${ }^{1}$, Shodmonov G.D. ${ }^{2}$ (Republic of Uzbekistan) Email: Mamatov344@scientifictext.ru
}

\author{
${ }^{I}$ Mamatov Farmon Murtozevich - Doctor of Technical Sciences, Professor, \\ DEPARTMENT OF AGRICULTURAL MECHANIZATION, HEAD OF THE DEPARTMENT, \\ DEPARTMENT OF SCIENTIFIC-APPLIED RESEARCHES AND INNOVATION; \\ ${ }^{2}$ Shodmonov Golib Dustmurodovich - PhD Researcher, \\ DEPARTMENT OF AGRICULTURAL MECHANIZATION, \\ KARSHI ENGINEERING-ECONOMICS INSTITUTE, \\ KARSHI, REPUBLIC OF UZBEKISTAN
}

\begin{abstract}
: the article considers the shortcomings of the traditional technology of soil preparation for sowing melons and gourds. With the traditional technology of preparing the soil for sowing melons and gourds, stepwise, i.e. Single-operation machines for several passes. One-operation technology for preparing soil for sowing includes fertilization, plowing, and preparation of soil for sowing. Then sowing melons and gourds is carried out. At the same time, labor productivity is reduced, labor and funds are expended, soil is compacted, soil preparation time is tightened, soil is intensively dried, which leads to a decrease in the yield of melons. The authors developed a new technology for preparing soil for sowing melons, combining the following technological operations: shallow surface loosening, cutting and displacement of soil with plant residues from the sowing zone, deep loosening, application of fertilizers and formation of irrigation grooves. To implement the proposed technology, a combined machine has been designed and manufactured. The use of the developed method of preparing soil for sowing melon crops and an aggregate for its implementation reduces the labor costs by 36,1 percent per each hectare of the area, the consumption of combustive-lubricating materials by 41,7 percent, and operating expenses by 39,7 percent.

Keywords: technology, soil, water-melons, machine, deep loosener, rink, crest, fuel consumption.

\section{ОБОСНОВАНИЕ КОНСТРУКТИВНОЙ СХЕМЫ КОМБИНИРОВАННОГО АГРЕГАТА ДЛЯ ПОДГОТОВКИ ПОЧВЫ К ПОСЕВУ БАХЧЕВЫХ Маматов Ф.М., Шодмонов Г.Д.² (Республика Узбекистан)}

\author{
${ }^{1}$ Маматов Фармон Муртозевич - доктор технических наук, профессор, \\ кафедра механизачии сельского хозяйства, \\ директор иентра, \\ Центр научно-прикладных исследований и инновачии \\ ${ }^{2}$ Шодмонов Голиб Дустмуродович - докторант, \\ кафедра механизации сельского хозяйства, \\ Каршинский инженерно-экономический институт, \\ г. Карши, Республика Узбекистан
}

\begin{abstract}
Аннотация: в статье рассмотрены недостатки традиционной технологии подготовки почвы к посеву бахчевых культур. При традиционной технологии подготовки почвы к посеву бахчевых культур проводится ступенчато, т.е. однооперачионныли машинами за несколько проходов. Однооперационная технология подготовки почвы к посеву предусматривает внесение удобрений, вспашку, подготовку почвы к посеву. Затем проводится посев бахчевых культур. При этом снижается производительность труда, увеличивается расходы труда и средств, происходит уплотнение почвы, затягивается сроки подготовки почвы, интенсивно высушивается почва, что влечет за собой снижение урожайности бахчевых культур. Авторами разработана новая технология подготовки почвы к посеву бахчевых, совмещающая следующие технологические операции: мелкое поверхностное рыхление, подрезание и смещение почвы с растительными остатками из зоны посева, глубокое полосное рыхление, внесение удобрений и формирование поливной борозды. Для осуществления предложенной технологии разработана и изготовлена комбинированная машина. Применение разработанного способа подготовки почвы к посеву бахчевых культур и агрегата для его осуществления способствует снижению на каждый гектар площади трудовых затрат на 36,1 прочента, расход горюче-смазочных материалов на 41,7 процента и эксплуатационных расходов на 39,7 процента.
\end{abstract}

Ключевые слова: технология, почва, бахчевые, машина, глубокорыхлитель, каток, гребня, расход топлива. 
Увеличение производства бахчевых культур и на этой основе дальнейшего повышения благосостояния населения республики является одной из главных задач сельского хозяйства. Решение этой задачи находится в прямой зависимости от эффективного использования земель, особенно почв изпод озимой пшеницы [1, с.21-25; 2, с.41-44; 3, с.16-19; 4, с. 267-269; 5, с.234-236].

Подготовка почвы к посеву и посев бахчевых культур проводится главным образом ступенчато, т.е. однооперационными машинами за несколько проходов. Однооперационная технология подготовки почвы к посеву предусматривает внесение удобрений, вспашку, подготовку почвы к посеву (дискование, боронование, малование и т.д.). Затем проводится посев бахчевых культур [7, с.264-266; 8, с.261-263; 9, с.10-11; 10, с.35-37; 11, с.27; 12, с.12-13; 13, с.125-126; 14, с.256-258].

Традиционная технология агрономически и экономически ничем не оправдана, так как снижается производительность труда, увеличивается расходы труда и средств, происходит уплотнение почвы, затягивается сроки подготовки почвы, интенсивно высушивается почва (особенно при посеве бахчевых под озимую пшеницу), что влечет за собой снижение урожайности бахчевых культур [15, с.58-63; 16, c.81-84; 17, c.86-88].

Необходимость своевременно в сжатые сроки качественная подготовка почвы, защиты почв от чрезмерного разрушения и уплотнения, проведения посева бахчевых культур в кратчайшие сроки вызвали разработки нового способа подготовки почвы после озимой пщеницы [18] и комбинированного агрегата для осуществления этого способа [19].

Предлагаемая технология включает следующие технологические операции: мелкое поверхностное рыхление, подрезание и оборот - смещение почвы зоны посева, глубокое полосное рыхление, внесение удобрений и формирование поливной борозды. Данная технология осуществляют следующим образом (рис.1). Вначале мелко поверхностно разрыхляют правой и левой стороны поля от оборачиваемых пластов, затем пласты почвы зоны посева оборачивают на разрыхленные полоса, после чего производят глубокое полосное рыхление зоны посева с одновременным внесением удобрений и формированием поливной борозды, причем толщина пластов почвы равна глубине поверхностного рыхления. При этом величина поперечного смещения центра тяжести пласта составляет не менее ширины его.

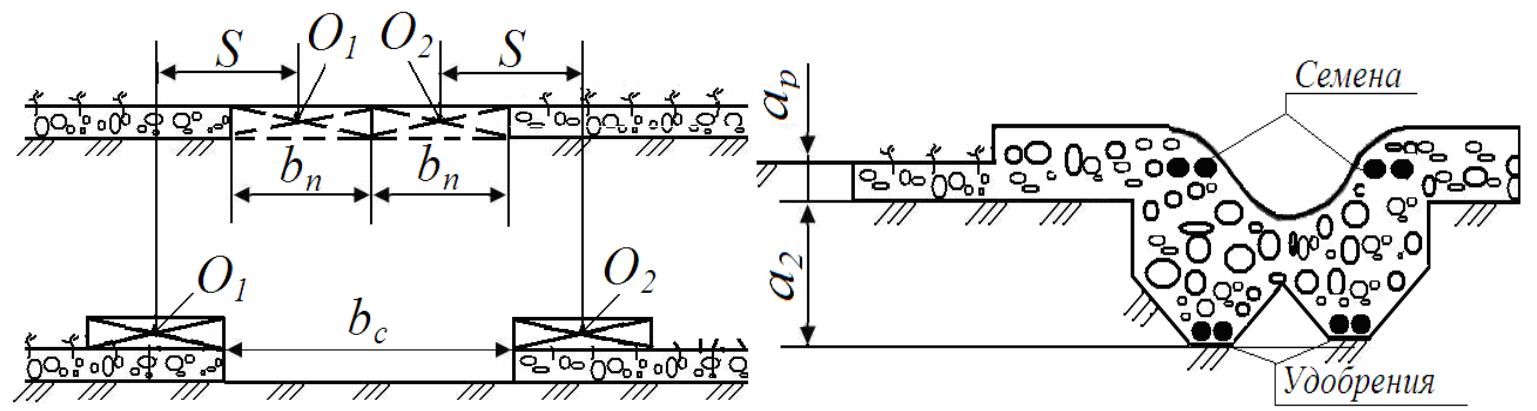

a)

б)

Рис. 1. Технологическая схема подготовки почвы к посеву бахчевых: а - профиль поперечного сечения поля после рыхления и оборота пластов; б - профиль поперечного сечения поля после глубокого рыхления почвы зоны посева, формирования поливных борозд

При обороте пластов почвы на разрыхленные полоса обеспечивается полное удаление из зоны посева растительностей. Из-за небольшой толщины пластов почвы значительно снижается расход энергии на оборот пластов. Глубокое полосное рыхление зоны посева с одновременным внесением удобрений и формированием поливной борозды позволяет качественное рыхление верхнего и подпахотного слоя почвы зоны посева и снижение энергоёмкости обработки почвы.

Для осуществления предложенной технологии нами разработан комбинированный агрегат (рис.2), которая содержит раму 1 , навесное устройство 2, дисковый нож 3, корпуса 4 листерного типа с направляющими пластинами 11 , рыхлители 6, глубокорыхлитель 7 с тукопроводом 8, катоквыравниватель 9 и высевающее устройство 10.

Глубокорыхлитель 6 выполнен типа «параплау», состоящей из двух стоек, отклоненных на разные стороны с левосторонними и правосторонними ножами и долотами на концах. На прямой части стойки глубокорыхлителя закреплены лево- и правооборачивающие отвалы - бороздоделатели 12. Рыхлители 5 и корпуса 4 с направляющими пластинами установлены на одном уровне.

Комбинированный агрегат работает следующим образом. Рыхлители 5 осуществляют мелкое поверхностное рыхление на глубину $\boldsymbol{a}_{\mathrm{p}}$ правую и левую полосу от зоны посева $b_{\mathrm{c}}$ (рис.1), затем дисковый нож 3 разрезая почву в вертикальной разделяет ее на две полосы, а корпуса 4 подрезают пласты с

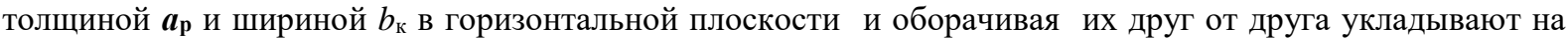
разрыхленные рыхлителями 6 полоса. В результате этого растительные остатки и их семена и корни 
полностью удаляются за пределы зоны посева. При этом корпуса смещают ценр тяжести пластов $O_{1}$ и $O_{2}$ на величину больше ширины пласта, т.е. $S>b_{n}$.

После чего глубокорыхлитель 7 внедряясь в подпахотный слой, разрыхляет почву зону посева. При этом одновременно с рыхлением вносится удобрения. Разрыхленная почва поступает на лево- и правооборачивающие отвалы 12 глубокорыхлителя 7. Отвалы-бороздоделатели 12 дополнительно разрыхляют и формируют поливную борозду. После чего осуществляется посев семена бахчевых высевающим аппаратом 10. Общая ширина захвата машины равна 3,6 м. Ширина захвата корпусов равна ширине зоны посева, т.е. 1,0-1,05 м. а ширина захвата рыхлителей 45 см.

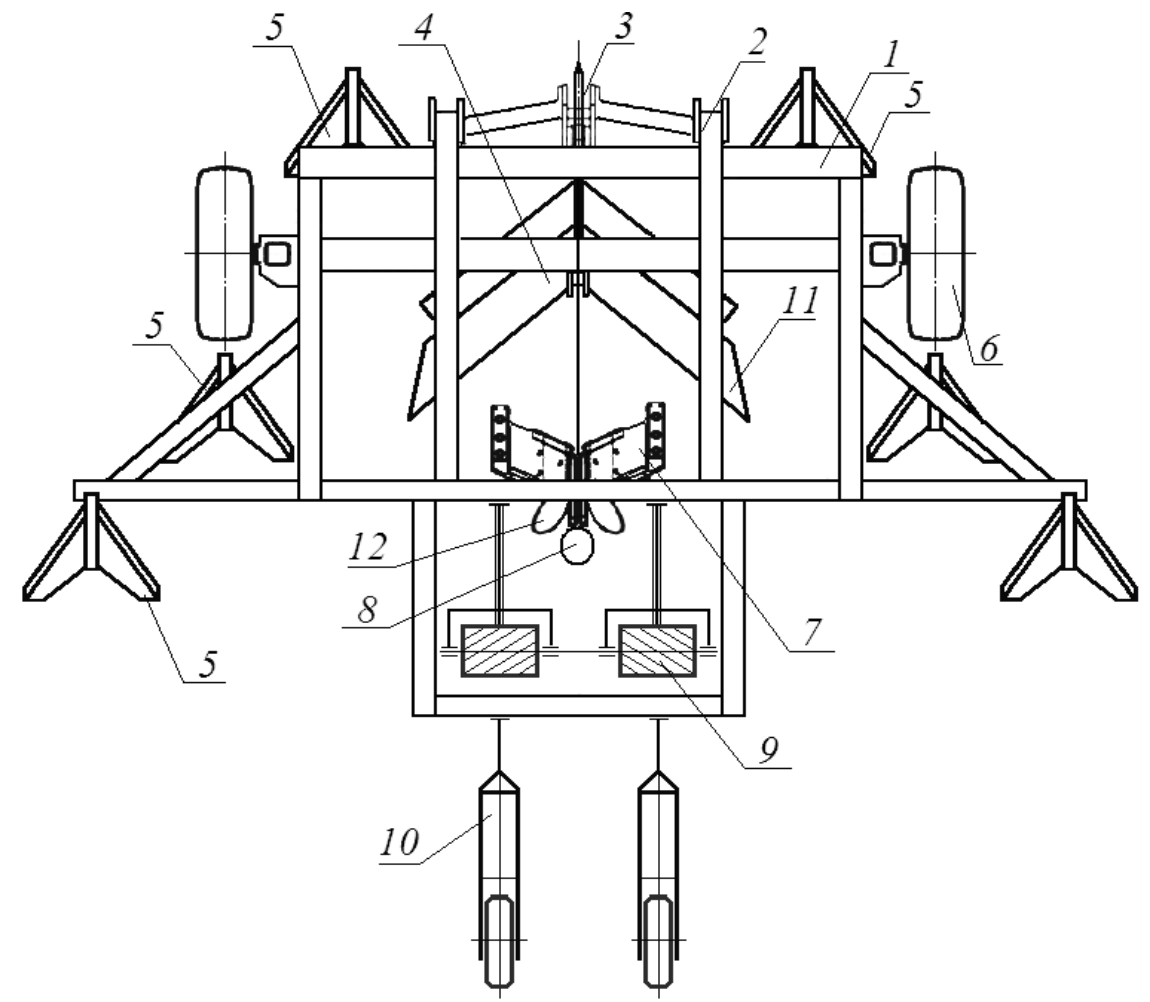

Рис. 2. Схема комбинированной машины для подготовки почвы к посеву бахчевых

В целом предлагаемая технология и комбинированный агрегат с минимальными затратами позволяет осуществлять качественную подготовку почвы и посев бахчевых культур.

Результаты испытаний и проведенные расчеты показали, что применение разработанного способа подготовки почвы к посеву бахчевых культур и агрегата для его осуществления способствует снижению на каждый гектар площади трудовых затрат на 36,1 процента, расход горюче-смазочных материалов на 41,7 процента и эксплуатационных расходов на 39,7 процента. Таким образом, предложенная технология подготовка почвы к посеву бахчевых и комбинированный агрегат для ее осуществления с наименьшими затратами осуществляет качественную подготовку почвы к посев бахчевых культур в сжатые сроки, способствует предохранению почвы от разрушения и чрезмерного уплотнения, снижению затрат труда и средств, повышению урожайности бахчевых культур.

\section{Список литературы / References}

1. Маматов Ф.М., Холияров Ё.Б., Курбанов Ш.Б., Рашидов Н.Ш. Перспективные технологии подготовки почвы к посеву на базе технологии гладкой безбороздной вспашки// European Research: Innovation in science, education and technology/ Collection of scientific articles. XXXVIII International scientific and practical conference. London, 2018. C. 21-25.

2. Дускулов А.А., Маматов Ф.М., Махмудов Х.С. Картофелепосадочная машина с роликовым и шнековым дозирующим аппаратом. European Research: Innovation in science, education and technology/ Collection of scientific articles. XXXIX International scientific and practical conference. London, 2018. P. 41-44.

3. Маматов Ф.М., Мирзаев Б.С. Новые противоэрозионные влагосберегающие технологии и орудия для обработки почвы в условиях Узбекистана// Экология и строительство. Москва, 2018. №4. С.16-19.

4. Mamatov F.M., Batirov Z.L., Xalilov M.S. Chisel-cultivator-fertilizer for forming ridges and applying fertilizers // Вена: European science review. - No. 3-4, 2018. P. 267-269. 
5. Mamatov F.M., Shodmonov G.D., Chujanov D.Sh., Ergashev G.X. New technology and combined machine for preparing soil for sowing gourds. Вена: European science review. No.1-2, 2018. P. 234-236.

6. Toshtemirov S.J., Mamatov F.M., Batirov Z.L., Chuyanov D.Sh., Ergashov G.Kh., Badalov S.M. Energyresource-saving technologies and machine for preparing soil for sowing. Вена: European science review. No. 3-4, 2018. P. 284-286.

7. Mamatov F.M., Ergashov G.Kh., Mirzaxodjayev Sh.Sh., Xoliyarov Y.B., Kurbanov Sh.B. Plow for smooth plowing with combined working bodies. Beна: European science review. No. 3-4, 2018. P. 264-266.

8. Mamatov F.M., Toshtemirov S.J., Xoliyarov Yo.B., Batirov Z.L. Energy-resource-saving technology and machine for preparing soil for planting cotton on the ridges // Вена: European science review. No. 3-4, 2018. P. 261-263.

9. Маматов Ф.М., Эргашев И.Т., Мирзаев Б.М., Мирзаходжаев Ш. Комбинированный фронтальный плуг// Сельский механизатор. Москва, 2011. № 10. С. 10-11.

10. Лобачевский Я.П., Маматов Ф.М., Эргашев И.Т. Фронтальный плуг для хлопководства// Хлопок. Москва, 1991. № 6. С. 35-37.

11. Маматов Ф.М., Чуянов Д.Ш., Мирзаев Б.С., Эргашев Г. Агрегат для новой технологии подготовки почвы под бахчевые культуры// Картофель и овощи. Москва, 2011. № 1. С. 27.

12. Маматов Ф.М., Чуянов Д.Ш., Мирзаев Б.М., Эргашев Г.Х. Агрегат для предпосевной обработки почвы// Сельский механизатор. Москва, 2011. № 7. С. 12-13.

13. Mamatov F.M., Kodirov U. Energy-resource saving machine for preparing soil for planting root crops on ridges//European Science Review. Vienna, 2016. No. 11-12. Page 125-126.

14. Маматов Ф.М., Мирзаев Б.С., Кодиров У. Почвозащитные энергоресрсосберегающие технологии и многофункциональный агрегат для обработки и подготовки почвы к посеву// Молодой учёный. Казань, 2013. № 10. С. 256-258.

15.маматов Ф.М., Мирзаев Б.С., Авазов И.Ж., Буранова Ш.У., Мардонов Ш.Х. К вопросу энергосберегающей противоэрозионной дифференцирированной системы обработки почвы//Инновации в сельском хозяйстве. Москва, 2016. № 3 (18). С. 58-63.

16. Мирзаев Б.С., Маматов Ф.М. Противоэрозионная технология гребнисто-ступенчатой вспашки и плуг для ее осуществления// Природообустройство. Москва, 2015. № 2. С. 81-84.

17. Маматов Ф.М., Мирзаев Б.С., Авазов И.Ж. Агротехнические основы создания противоэрозионных влагосберегающих технических средств обработки почвы в условия Узбекистана// Природообустройство. Москва, 2014. № 4. С. 86-88.

18. Патент РУз № IAP 05360. Способ подготовки почвы и посева / Маматов Ф.М., Мирзаев Б.С., Чуянов Д.Ш., Эргашов Г.Х., Шодмонов Г., Тоштемиров С.Ж., Буранова Ш.У., Кузиев Н.М. // Расмий ахборотнома. 2017. №4. С.23.

19. Патент РУз № FAP 01125. Комбинированное почвообрабатывающее орудие / Маматов Ф.М., Мирзаев Б.С., Чуянов Д.Ш., Эргашов Г.Х., Кодиров У.И., Тоштемиров С.Ж., Буранова Ш.У., Шодмонов Г.Д. // Расмий ахборотнома. 2016. №6. С.17. 